\title{
Research Paper: A Retrospective Observational Study of Accidental Carbamate Poisoning Among Children Referred to a Tertiary Care Center in Rural Maharashtra, India
}

\author{
Rama Krishna Sanjeev $^{1^{*}}$, Mohan Nagorao Pawar $^{2}$, Divyank Sharma ${ }^{3}$
}

1. Department of Pediatrics, Rural Medical College, Pravara Institute of Medical Sciences, Maharashtra, India.

2. Department of Forensic Medicine and Toxicology, Rural Medical College, Pravara Institute of Medical Sciences, Maharashtra, India.

3. Paediatrician, JM Nursing Home, Seohara, Dist Bijnor, Uttar Pradesh, India.

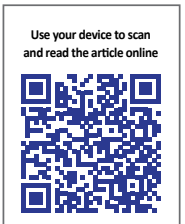

Citation: Sanjeev RK, Pawar MN, Sharma D. A Retrospective Observational Study of Accidental Carbamate Poisoning Among Children Referred to a Tertiary Care Center in Rural Maharashtra, India. International Journal of Medical Toxicology and Forensic Medicine. 2019; 9(3):141-150. https://doi.org/10.32598/ijmtfm.v9i3.26179

https://doi.org/10.32598/ijmtfm.v9i3.26179

\section{(a) 03}

Article info:

Received: 05 Jan 2019

First Revision: 23 Jan 2019

Accepted: 22 Apr 2019

Published: 01 Jul 2019

\section{Keywords:}

Pesticides, Poisoning, Carbamates, Carbofuran, Pediatrics

\section{ABSTRACT}

Background: Carbofuran is a widely-used carbamate insecticide which is listed as highly hazardous (Class 1b) by the World Health Organization (WHO) classification of pesticides. We report the poisonings among children following exposure to carbofuran crystal form, which is used as a household remedy for head lice infestation.

Methods: The medical case records from June 2016 to January 2019 of a Tertiary Care Hospital in rural Maharashtra, India, were examined for the pediatric poisoning due to exposure to blue crystals in sachets being sold as medication for head lice infestation and its confirmation as being carbofuran. A total of 14 such exposures were found among 64 cases of pediatric poisoning (excluding bites and sting envenomation), recorded in the above period. The children were evaluated for their presentations, manner of unintentional poisonings, clinical profile, and outcomes.

Results: The results in carbofuran poisonings showed universal unintentional exposure with the majority of patients being infants and toddlers. It was the most significant single cause of poisoning, excluding bites and envenomation, in the above period. The clinical features of excessive cholinergic activity were consistent with the characteristics of carbamate poisoning. Comparison with other poisonings during the period did not show significant differences concerning variables such as age, sex, religion, and length of hospital stay.

Conclusion: Unintentional poisoning of the class1 pesticide carbofuran, among younger children, is associated with misuse and availability in the environment. Our obtained data about the agent, host, and environmental factors related to the poisoning are consistent with data available on the literature.

* Corresponding Author:

Rama Krishna Sanjeev, MD.

Address: Department of Pediatrics, Rural Medical College, Pravara Institute of Medical Sciences, Maharashtra, India.

Tel: +91 (999) 0147389

E-mail: rksanjeev88@yahoo.com 


\section{Introduction}

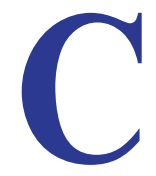

arbofuran is a systemic carbamate insecticide classified as highly hazardous (Class $1 \mathrm{~b}$ ) by the World Health Organization (WHO) classification of pesticides. It has an (LD50) value of $8 \mathrm{mg} / \mathrm{kg}$ (The LD50 value is an estimated amount of the chemical required to kill ( $50 \%$ ) of a large population of test animals, usually rats) [1]. Carbofuran has been registered and marketed in a granular form $(3 \mathrm{G})$ in India. The preference for carbofuran $3 \mathrm{G}$ (the granular form with $(3 \%)$ concentration) is apparently due to the low level of occupational exposure, low risk of inhalation, and reduced dermal toxicity by skin exposure [2]. Over the past four decades, carbofuran has commonly been used as an insecticide, nematicide, and acaricide. Carbofuran poisoning among humans is known by both accidental and intentional exposure. Among animals, the poisoning has been reported due to malicious exposure across several countries [3].

Organophosphate and carbamate compounds act by inhibiting acetylcholinesterase, thereby increasing acetylcholine level at the nerve endings. Their exposure by accidental or intentional poisoning causes the syndrome of excessive cholinergic activity of miosis, increased salivation, excessive respiratory secretions, diarrhea, emesis, paralysis, respiratory depression, and other similar effects (muscarinic, nicotinic, central) $[3,4,5]$. This study was carried out after frequent poisonings were noted due to crystals sold in the local markets for pediculosis treatment in a busy Tertiary Care Hospital in rural Maharashtra, India. The Hospital provides free services to children with a large number of pediatric emergencies being treated regularly.

Children are uniquely vulnerable than adults to the effects of pesticides because of greater hand to mouth proclivity, more food and water requirements per $\mathrm{kg}$ body weight as well as developmental or physiological factors [6]. Middle- and lowincome countries have up to four times higher mortality to pesticide exposure among children. Pesticide poisoning (intentional or accidental) is a serious problem in the agricultural communities of low- and middle-income countries such as China, India, and Sri Lanka [7].

Inappropriate use and storage of pesticides is a crucial issue contributing to pesticide poisonings among children, particularly in agricultural communities in developing countries where such poisonings are common [8]. Even when poisoning as a cause is correctly diagnosed, the health care personnel may not know the toxic agent responsible [9]. Among insecticides, occupational exposure usually occurs by inhalation (pulmonary) or dermal routes, while oral ingestion is the most common cause of non-occupational poisoning [9].
Poisoning causation is multifactorial and diverse. The Haddon matrix has been used as a tool in evaluating the factors contributing to injury prevention in the context of pesticide poisoning [10]. This procedure is done by systematically dividing the agent, host, and environmental factors involved in three groups, namely, pre-event, event, and post-event. We tried to do the same here in the context of carbofuran poisoning.

Objectives: We aimed to study the pattern of poisonings due to exposure to sachet containing blue granules of carbofuran among children, based on the medicolegal case records of Rural Medical College, Pravara Institute of Medical Sciences from June 2016 to January 2019.

\section{Materials and Methods}

After Institutional Ethics Committee approval, case records of the pediatric patients presenting to the Hospital due to poisoning attributed to blue granules in sachets, from June 2016 till Jan 2019 were examined. Their demographic details, manner of intoxication, mode of presentation, outcome, and treatment given were collected. The relevant demographic data for other poisonings in the same period like age, sex, religion, length of hospital stay, mortality outcome, and intention (whether suicidal or accidental) were also collected for comparison. Care was taken to maintain patient confidentiality.

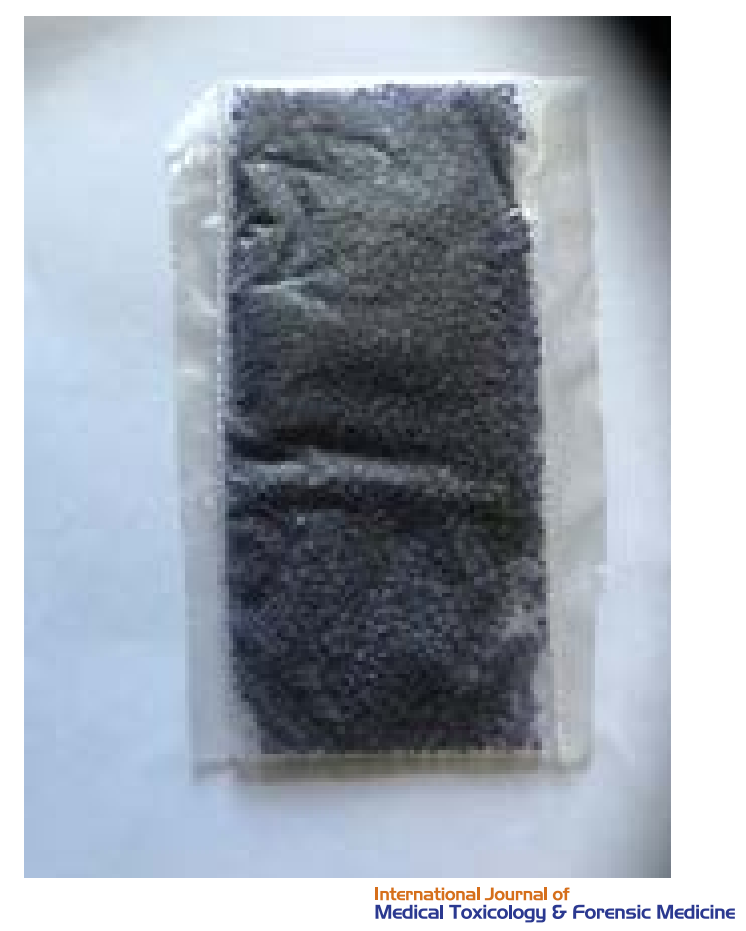

Figure 1. Sachet containing Carbofuran 3G granules 
The carbofuran poisoning was due to blue granules (sold in small rectangular transparent plastic sachets measuring about 4 by $2 \mathrm{~cm}$ ), (Figure 1) purchased from the market for about a ( $\square 10 /$ - Indian Rupee). The samples collected from the relatives of the patients were studied.

Inquiries from the parents of the patients revealed that the poison was available in the local markets as a remedy for lice infestation and sold for application after adding it to a container containing coconut oil. The supernatant oil was used for application. The oil was effective for head louse infestation after about two or three overnight applications. It was removed by bathing in the morning. The granules in the sachet do not change the color of oil on addition (Figure 2). The children usually picked the crystals from the opened sachets and consumed it. We did not come across any report of anyone being affected after application in the scalp.

Gastric lavage samples sent for analysis did not reveal the nature of the poison. The granules in sachets were sent for

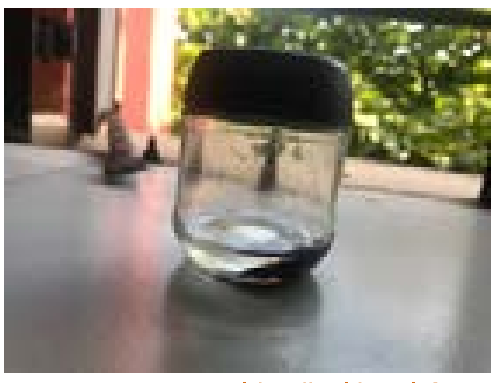

International Journal of
Medical Toxicology \& forensic Medicine Figure 2. Carbofuran granules in coconut oil with no change in colour of oil. Supernatant oil was used for application.

analysis to Regional Forensic laboratory, Nashik and they confirmed the presence of carbamate insecticide carbofuran (2, 2-dimethy 1-2, 3-dihydro-1-benzofuran-7-yl-methyl carbamate). Though carbofuran is reported in the literature as a white crystalline solid, the industrial form of (3\%) carbofuran is in the blue granular form (personal communication with Prof Ramesh Gupta, Prof \& Head of Toxicology, Murray State University).

Table 1. Pediatric poisoning by type over the period from June 2016 till Jan 2019 excluding bites and envenomations

\begin{tabular}{|c|c|c|c|}
\hline \multirow{2}{*}{ Types of Poisoning } & \multirow{2}{*}{ Frequency } & \multicolumn{2}{|c|}{$\%$} \\
\hline & & Percent & Cumulative \\
\hline Adsul & 1 & 1.6 & 1.6 \\
\hline Aluminum sulfide & 1 & 1.6 & 3.2 \\
\hline Amitraz & 2 & 3.2 & 6.4 \\
\hline Biozyme & 1 & 1.6 & 8.0 \\
\hline Camphor & 1 & 1.6 & 9.6 \\
\hline Carbofuran & 14 & 22 & 31.6 \\
\hline Carbolic acid & 1 & 1.6 & 33.2 \\
\hline Cypermethrin & 2 & 3.2 & 36.4 \\
\hline Datura & 2 & 3.2 & 39.6 \\
\hline Floor cleaner & 1 & 1.6 & 41.2 \\
\hline Iron tablet & 1 & 1.6 & 42.8 \\
\hline Lambda-cyhalothrin & 1 & 1.6 & 44.4 \\
\hline Murtox (Deltamethrin) & 1 & 1.6 & 46.0 \\
\hline Naphthalene & 1 & 1.6 & 47.6 \\
\hline Nitrobenzene & 1 & 1.6 & 49.2 \\
\hline OPP & 14 & 22 & 71.2 \\
\hline
\end{tabular}




\begin{tabular}{|c|c|c|c|}
\hline \multirow{2}{*}{ Types of Poisoning } & \multirow{2}{*}{ Frequency } & \multicolumn{2}{|c|}{$\%$} \\
\hline & & Percent & Cumulative \\
\hline Paint thinner & 1 & 1.6 & 72.8 \\
\hline Petrol & 1 & 1.6 & 74.4 \\
\hline Quizalofop ethyl 5\% & 1 & 1.6 & 76.0 \\
\hline Rat poison & 1 & 1.6 & 77.6 \\
\hline Soil containing fertilizer & 1 & 1.6 & 79.2 \\
\hline Sulphuric acid (battery) & 1 & 1.6 & 80.8 \\
\hline Thymate (phorate) & 1 & 1.6 & 82.4 \\
\hline Unknown substance & 4 & 6.4 & 88.8 \\
\hline Unknown seed & 2 & 3.2 & 92.0 \\
\hline Unknown tablet & 3 & 4.8 & 96.8 \\
\hline White rat poison & 1 & 1.6 & 98.4 \\
\hline Zinc phosphide & 1 & 1.6 & 100.0 \\
\hline Total & 64 & 100.0 & 100.0 \\
\hline
\end{tabular}

\section{Statistical analysis}

Data coding and entry was done in Microsoft Excel spreadsheet. The descriptive and inferential statistical analysis was done in SPSS V. 21. In descriptive statistics, mean, median, standard deviation, and percentage were calculated. The inferential statistical analysis was done using the Chi-Square test, Mann-Whitney U test, and Fisher t-test. The level of significance was considered $(<0.05)$.

\section{Results}

A total of 64 patients, aged less than 12 years, were brought to the Hospital with poisoning (excluding stings and snake envenomation) in the period studied. Out of them, 14 were due to other organophosphate compounds, and 14 were due to carbofuran. The other poisonings were a heterogeneous mixture of pesticides, natural poisons like Datura, household chemicals, and drugs (Table 1). In 7 cases, the poison (or tablet consumed) was unknown. These figures make carbofuran the most frequent single type of poisoning in the study period in the studied population. The patients' details for carbofuran are presented in Table 2 .
The average age of the patients with carbofuran poisoning was 3 years with the youngest being 6 months and eldest 8 years. The predominant sex to which the patients consumed sachets containing carbofuran belonged to male gender (11 out of the 14).

All the poisonings for carbofuran could be classified as accidental oral intake. The poison was given by their elder sibs to two infants aged 6 months and 15 months, but all others picked the poison themselves. This condition included an 11 months female infant who found the poison lying in the sachet at home and consumed it. Only two (14\%) children were younger than 1 year, and 2(14\%) were older than 5 years. All except 3 children consumed the poison after they found it lying around in a sachet at home. The sachets were purchased from the local market by their parents for lice treatment in 11 out of 14 cases. Two children found the used sachet lying in a rubbish heap and consumed it, and shared it at home with their infant sister. Both these methods of taking the poison, suggest the ubiquity of this poison. All the patients were brought to the Hospital on being symptomatic at home or after parents knew they consumed the poison.

Pre-hospital treatment was given to 3 of the children with carbofuran poisoning with all 3 receiving atropine 


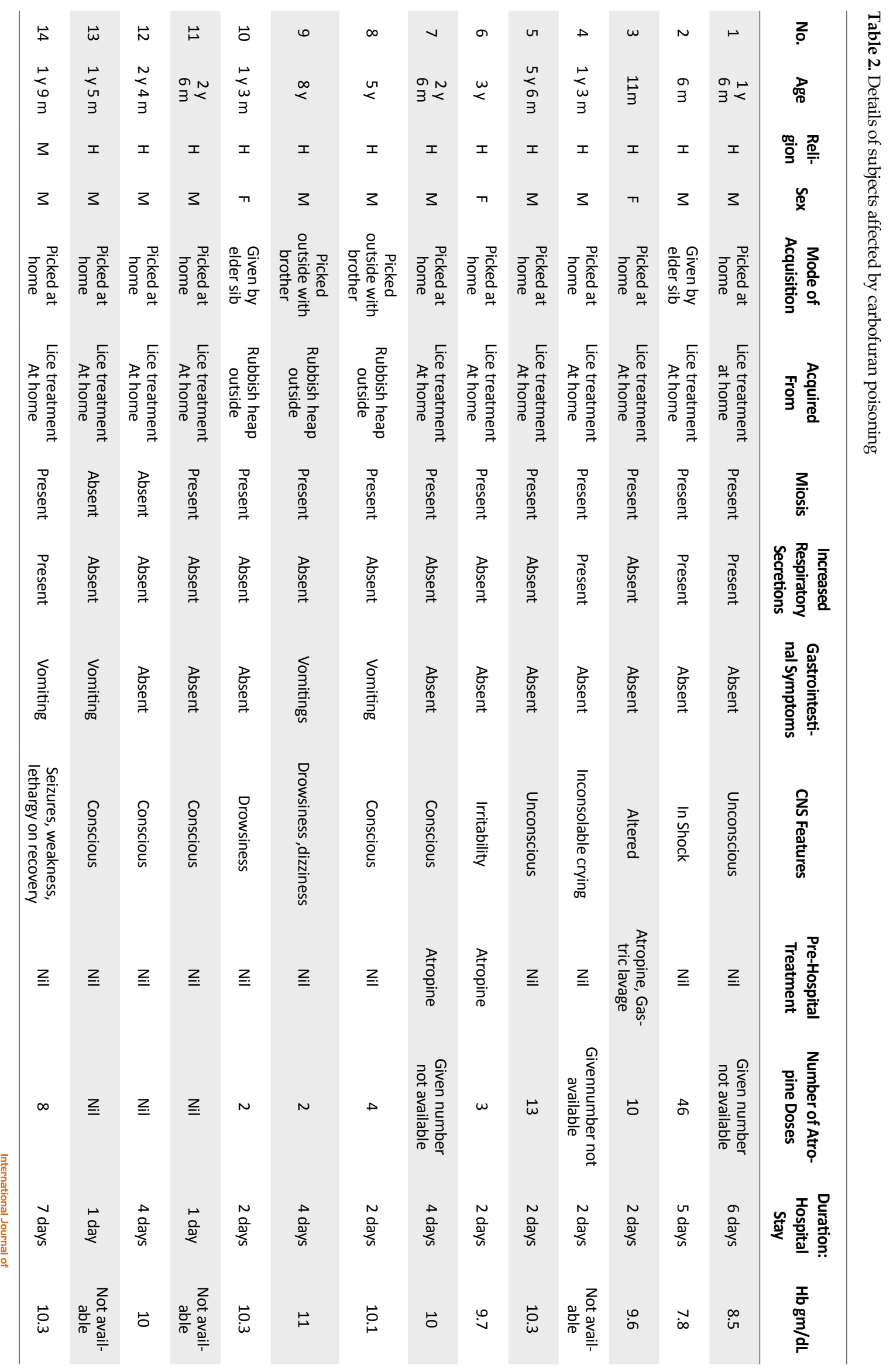


Table 3: Frequency of carbofuran and other poisonings by sex

\begin{tabular}{ccccc}
\hline & \multicolumn{2}{c}{ Sex } & Total \\
\cline { 2 - 4 } Type of poisoning & Female & Male & 50 \\
\hline Other & 21 & 11 & 14 \\
Carbofuran & 3 & $40(62.5 \%)$ & $64(100 \%)$ \\
\hline Total & $24(37.5 \%)$ & 29 & \multirow{2}{*}{} \\
\hline
\end{tabular}

The Chi square test: $\chi^{2}=1.97 ; \mathrm{df}=01 ; \mathrm{P}=0.16$ non-significant

Table 4: Comparing the frequency of poisoning concerning the religion of the patients

\begin{tabular}{ccccc}
\hline \multirow{2}{*}{ Type of Poisoning } & \multicolumn{3}{c}{ Religion } & Total \\
\cline { 2 - 4 } & Hindu & Muslim & 50 \\
\hline Other & 43 & 07 & 14 \\
\hline Carbofuran & 13 & 01 & 64 \\
\hline Total & 56 & 08 & 64 \\
\hline
\end{tabular}

The Chi-square test: $\chi^{2}=0.05 ; \mathrm{df}=1 ; \mathrm{P}=0.81$ non-significant

Table 5. Comparing carbofuran and other poisonings concerning mortality

\begin{tabular}{cccc}
\hline Event & Other Poisonings & Carbofuran & Total \\
\hline Mortality & 4 & 0 & 4 \\
\hline Frequency & 50 & 14 & 64 \\
\hline
\end{tabular}

Fisher exact value for mortality; $\mathrm{P}=0.56$ non-significant

International Journal of
Medical Toxicology \& Forensic Medicine

and 1 receiving both atropine and gastric lavage. Twelve (85.7\%) were recorded as having miosis at admission. There were increased respiratory secretions and gastrointestinal symptoms present among $4(28.5 \%)$ cases. Three were brought unconscious, and one 15 months old was crying inconsolably. Two (14\%) had seizures with unconsciousness requiring phenytoin at admission. One (7\%) 17 months old needed ventilation for 18 hours. Pralidoxime was given to 4 out of 14 (which was before it was known that the poison was carbamate). Most (11 out of 14: 78.5\%) children were treated with doses of atropine with one having received 46 doses (Table 9) (including the minimum and maximum atropine doses as well as Mean $\pm \mathrm{SD})$. The mean length of hospital stay was 3.5 days with the maximum of 8 days and the minimum of 1 day. Seven $(50 \%)$ children were hospitalized for two days. All patients with carbofuran poisoning survived, but 4 patients, with other poisonings, expired (Tables 3, 4, 5, 6, 7, 8). Time of ingestion to admission could not be reliably determined in many patients from the records and was not included.

Table 6. Comparing the intention of poisoning between Carbofuran and other poisonings

\begin{tabular}{cccc}
\hline Poisoning Intention & Other Poisoning & Carbofuran & Total \\
\hline Suicidal & 3 & 0 & 3 \\
\hline Frequency & 50 & 14 & 64 \\
\hline Fisher exact value for intention of poisoning, $\mathrm{P}=0.0001$ non-significant & & $\begin{array}{c}\text { International Journal of } \\
\text { Medical Toxicology \& Forensic Medicine }\end{array}$
\end{tabular}


Table 7. Comparing carbofuran and other poisonings concerning the mean age

\begin{tabular}{ccr}
\hline Age Variable & Other Poisoning & Carbofuran \\
\hline Mean $\pm S D, y$ & $3.30 \pm 2.85$ & $2.98 \pm 2.32$ \\
Range & 0.11 month to 11.00 years & 6 months to 8 years \\
\hline The independent t-test: $0.384 ; \mathrm{df}=62 ; \mathrm{P}=0.70$ non-significant & $\begin{array}{l}\text { International Journal of } \\
\text { Medical Toxicology \& Forensic Medicin }\end{array}$
\end{tabular}

Table 8. Comparing carbofuran and other poisonings concerning the duration of hospitalization

\begin{tabular}{ccc}
\hline Hospital Stay & Other Poisoning & Carbofuran \\
\hline Mean $\pm S D, d$ & $2.32 \pm 1.99$ & $3.07 \pm 1.81$ \\
Range & $1-10$ days & $1-7$ days \\
\hline The independent t-test: $1.26 ; \mathrm{df}=62 ; \mathrm{P}=0.20$ non-Significant & $\begin{array}{c}\text { International Journal of } \\
\text { Medical Toxicology \& Forensic Medicin }\end{array}$
\end{tabular}

\section{Discussion}

The fundamental aphorism of toxicology attributed to Paracelsus is "the right dose differentiates a poison and a remedy" [11]. Here, the granular carbofuran is dangerous when ingested by the child but curative for head lice infestation in diluted form as is taken by adults. Inhalational carbofuran poisoning by occupational exposure among workers has also been reported but with the powder form $[2,12]$.

In applying the Haddon matrix to carbofuran poisoning, as shown by Eddleston et al. the preventable issues can be elucidated within agent, host, and environmental causes under pre-event, event, and post-event factors $[8,10]$. The factors pertinent to this poisoning are listed in the Haddon Matrix in Table 10.

\section{Host factors:}

The majority of the children were infants and toddlers, with 11 out of $14(78.5 \%)$ aged three years and younger. For the child, the issues will be age; for example, the toddlers have their exploratory nature or the younger curious child exploring a dustbin. Gender of the child will be relevant as boys have higher exploratory behavior [9]. Here, 11 of the

Table 9. Atropine dose in children with carbofuran poisoning

\begin{tabular}{ccc}
\hline Number of Atropine Doses & No. & $\%$ \\
\hline 1 & 1 & 7.1 \\
13 & 1 & 7.1 \\
\hline 2 & 2 & 14.3 \\
3 & 1 & 7.1 \\
\hline 4 & 1 & 7.1 \\
\hline 46 & 1 & 7.1 \\
\hline 8 & 1 & 7.1 \\
\hline Few & 1 & 7.1 \\
\hline Number not recorded but given & 2 & 14.3 \\
\hline Total & 3 & 21.4 \\
\hline Mean doses of Atropine 0.11 ; The median doses of Atropine: 0.06 & 14 & 0.001 \\
\hline
\end{tabular}


Table 10. Haddon matrix depicting probable causes behind poisoning studied

\begin{tabular}{|c|c|c|c|}
\hline Phase & Host & Agent & Environment \\
\hline Pre-event & $\begin{array}{l}\text { Poverty, anemia (causing pica), } \\
\text { working parents (agricultural } \\
\text { labor, etc.), exploratory behavior, } \\
\text { impulsivity, lack of knowledge } \\
\text { about nature of agent and lethal- } \\
\text { ity, comorbidities like malnutrition }\end{array}$ & $\begin{array}{l}\text { Agent transferred to another con- } \\
\text { tainer from the original } \\
\text { parental use of carbofuran gran- } \\
\text { ules as lice killer, } \\
\text { lack of parental insight into dan- } \\
\text { ger to children by agent leaving } \\
\text { agent lying around }\end{array}$ & $\begin{array}{l}\text { Staying in a rural environment } \\
\text { with poor waste disposal, lice } \\
\text { infestation in community, } \\
\text { The availability of insecticides for } \\
\text { the illegal manufacture of sachets }\end{array}$ \\
\hline Event & $\begin{array}{l}\text { Unsupervised } \\
\text { thereby picking up of sachet fol- } \\
\text { lowed by consumption }\end{array}$ & $\begin{array}{l}\text { Color (blue) attracting child Dose } \\
\text { ingested }\end{array}$ & $\begin{array}{l}\text { Proximity to other people during } \\
\text { the attempt }\end{array}$ \\
\hline Post-event & $\begin{array}{l}\text { Recognition of consumption by } \\
\text { the parents, } \\
\text { Recognition of illness by parents }\end{array}$ & $\begin{array}{c}\text { Availability of antidotes and } \\
\text { ventilators }\end{array}$ & $\begin{array}{c}\text { Access/transport to hospital care, } \\
\text { Availability of free tertiary medi- } \\
\text { cal care, } \\
\text { Recognition of poisoning syn- } \\
\text { drome by the caregiver }\end{array}$ \\
\hline
\end{tabular}

14 subjects were male. Detailed socioeconomic history was not recorded, but pediculosis has been reported in developing countries among lower socioeconomic strata [13].

The parents belonging to the lower socioeconomic strata might seek treatment through nonmedical channels for pediculosis. Three children who acquired the poison while foraging through the rubbish are likely to be from a lower socioeconomic class. Studies have unequivocally shown the association between toxic exposure and poverty [14]. The religion of the majority of the children was Hindu with only 1 child (7\%) being Muslim, which is consistent with census data of the district (Ahmednagar, Maharashtra) [15].

Pica, by definition, is the ingestion of non-nutritive materials such as clay, dirt, etc. and is common in children with iron deficiency. Though iron studies and hematological evaluation in carbofuran poisoning patients was not done, anemia affected 10 out of 11 children whose hemoglobin levels were available $(<11 \mathrm{gm} / \mathrm{dL})$. Presence of pica could have contributed to the ingestion of the poison in some of them [16].

The clinical features showed that miosis was present in the majority $(85.7 \%)$ of cases and gastrointestinal as well as respiratory secretions were present in $4(28.5 \%)$ cases. Atropine was given to 11 out of $14(78.5 \%)$ cases. A study on organophosphate and carbamate poisoning showed that $(92 \%)$ having received atropine and (38\%) required intubation and mechanical ventilation [4]. However, only one patient required ventilation in our study.

\section{Agent factors}

Carbofuran belongs to a class $1 \mathrm{~b}$ pesticide and is highly poisonous as per the WHO classification of pesticides [1]. The classification is meant for occupational exposure by dermal and inhalational routes and is based on rat studies. Studies have shown low dermal toxicity of carbofuran $3 \mathrm{G}$, which is the granular form [2]. Our sample of poison was in the granular form and toxicologically proven to contain carbofuran and hence most likely is carbofuran $3 \mathrm{G}$. The occupational risk by dermal exposure is acceptable for this formulation compared to the liquid form in spite of its belonging to a highly poisonous category.

Nevertheless, pesticide poisoning studies in South Asia have shown the merits of this classification by WHO $[1,7$, 17]. An unlabeled chemical will also be subject to less vigilance by adults in comparison to a labeled compound. Organophosphates like malathion, a class 3 pesticide, have been utilized for the treatment of head louse infestation. There have been reports of poisoning by hazardous pesticide following application for Pediculosis due to dermal absorption $[18,19]$. However, contrary to the report by Hamad et al. our results confirmed oral exposure by children following the insecticide use for pediculosis by parents. We could not come across a pattern of exposure like ours among children in the literature reviewed.

Here, the pesticide was not directly applied, but it was used with the coconut oil for application. There was no change in color when we put the blue crystals obtained locally from the market in coconut oil for a few hours (Figure 2). Carbofuran itself is a white, crystalline solid compound. Carbamates are generally more soluble in polar than nonpolar organic solvents [20].

Similarly, transferring the pesticide from its original container to another container is a significant risk factor in the 
causation of pediatric poisoning $[8,21]$. For post-event, the recognition of the toxidrome by the hospital or health care staff and the availability of effective antidote (atropine) in this instance were lifesaving.

\section{Environmental factors:}

Pre-event factors which could have contributed to the poisoning would be staying in rural areas with availability and ubiquity of use of pesticides. Similarly, the absence of waste disposal could have resulted in partially used pesticide containing sachets lying around. Inadequate primary health care services in rural areas could have led the adults to seek treatment pediculosis by the above-discussed means. During the event itself, the proximity of caring adults led to the recognition of poisoning and seeking health care services appropriately. Interestingly, though the patients came from a wide geographic area around $\mathrm{Ru}$ ral Medical College, only 3 out of 14 had received prehospital care of atropine and gastric lavage. Since the Institute provides free tertiary level care, it is assumed that the parents used available transport services to get the children to the Hospital swiftly rather than seek pre-hospital care. Alternatively, there could be non-availability of adequate care in proximity to the rural clientele.

The issue of the availability of carbofuran and familiarity with its use, as suggested here, could be explained by the pesticide consumption patterns in Maharashtra. In this state, cotton, sugarcane, fruits, and vegetables are commonly grown (which account for the bulk of the share of pesticides used in the country). Among the 29 states in India, after Uttar Pradesh, Maharashtra consumes the second highest tonnage of pesticide per year. Moreover, the state has the highest number of retail points $(19 \%)$ in all states in India. The majority of sales outlets for pesticides in the country come from the private sector, with profit being the sole motive [22].

Interestingly, in the US, the first banned form of carbofuran was the granular one on environmental grounds [23]. This kind of poisoning among children is associated with the ubiquity of pesticide availability in rural areas in developing countries [24]. There are tremendous risks to the community and environment by the formulation. Epidemiologically, the question of banning such a formulation can be compared to removing the handle of the Broad Street water pump in 1853 during the London Cholera epidemic [25, 26, 27]. As the experience of neighboring Sri Lanka and Bangladesh shows, banning highly hazardous pesticides could be similarly rewarding [28].
Limitations of the study: Serum acetylcholinesterase and the poison level were not measured due to resource constraints. Though the first author was working in the Pediatric ICU since March 2017 and managed most of the patients mentioned in the study, the study data were extracted from case files after due permission from the Institution, retrospectively.

\section{Conclusion}

We studied the poisoning due to the granular form of carbofuran among children less than 12 years, being misused for treatment of pediculosis in rural Maharashtra, India. The type of poisoning suggests that in rural areas of developing countries, the highly hazardous pesticides are common causes of accidental poisoning among children apart from suicides in adults and is associated with the ready availability of the pesticide.

\section{Ethical Considerations}

\section{Compliance with ethical guidelines}

All relevant data, regarding patients, were kept confidential, including tables in the manuscript.

\section{Funding}

This research did not receive any specific grant from funding agencies in the public, commercial, or not-for-profit sectors.

\section{Author's contributions}

Conceptualization and supervision: Rama Krishna Sanjeev, Mohan Nagorao Pawar; Writing original draft: Rama Krishna Sanjeev; Methodology, review and editing: Rama Krishna Sanjeev, Mohan Nagorao Pawar, Divyank Sharma; resources: Rama Krishna Sanjeev, Mohan Nagorao Pawar, Divyank Sharma.

\section{Conflict of interest}

The authors declared no conflict of interest.

\section{Acknowledgements}

We thank the Medical records section, Rural Medical College, Pravara Institute of Medical Sciences for allowing access to the Medicolegal records for the study period. We also thank Regional Forensic Laboratory Nashik for valuable help in identification of the pesticide as carbofuran. We thank Dr. Anup Kharde and Dr. Kalpak Kadarkar, Preventive Medicine Specialists, for assistance in statistical analysis in the study. 


\section{References}

[1] World Health Organization. The WHO recommended classification of pesticides by hazard and guidelines to classification 2009 Geneva: World Health Organization; 2009.

[2] Gammon DW, Liu Z, Becker JM. Carbofuran occupational dermal toxicity, exposure and risk assessment. Pest Management Science. 2012; 68(3):362-70. [DOI:10.1002/ps.2270] [PMID] [PMCID]

[3] Gupta RC. Carbofuran toxicity. Journal of Toxicology and Environmental Health. 1994; 43(4):383-418 [DOI:10.1080/15287399409531931] [PMID]

[4] Zwiener RJ, Ginsburg CM. Organophosphate and carbamate poisoning in infants and children. Pediatrics. 1988; 81(1):121-6.

[5] Roberts JR, Karr CJ. Pesticide exposure in children. Pediatrics. 2012; 130(6):e1765-88. [DOI:10.1542/peds.2012-2758] [PMID] [PMCID]

[6] Fukuto TR. Mechanism of action of organophosphorus and carbamate insecticides. Environmental Health Perspectives. 1990; 87:245-54. [DOI:10.1289/ehp.9087245] [PMID] [PMCID]

[7] Jeyaratnam J. Acute pesticide poisoning: A major global health problem. World Health Statastical Quarterly. 1990; 43:139-44.

[8] Branche C, Ozanne-Smith J, Oyebite K, Hyder AA. World report on child injury prevention. Geneva: World Health Organization; 2008.

[9] Hyder AA, Sugerman DE, Puvanachandra P, Razzak J, ElSayed H, Isaza A, et al. Global childhood unintentional injury surveillance in four cities in developing countries: A pilot study. Bulletin of the World Health Organization. 2009; 87(5):345-52. [DOI:10.2471/BLT.08.055798] [PMID] [PMCID]

[10] Eddleston M, Buckley NA, Gunnell D, Dawson AH, Konradsen F. Identification of strategies to prevent death after pesticide self-poisoning using a Haddon matrix. Injury Prevention. 2006; 12(5):333-7. [DOI:10.1136/ip.2006.012641] [PMID] [PMCID]

[11] Grandjean P. Paracelsus revisited: The dose concept in a complex world. Basic \& Clinical Pharmacology \& Toxicology. 2016; 119(2):126-32. [DOI:10.1111/bcpt.12622] [PMID] [PMCID]

[12] McConnell R, Hruska AJ. An epidemic of pesticide poisoning in Nicaragua: Implications for prevention in developing countries. American Journal of Public Health. 1993; 83(11):1559-62. [DOI:10.2105/AJPH.83.11.1559] [PMID] [PMCID]

[13] Chaudhry S, Maqbool A, Ijaz M, Ahmad N, Latif M, Mehmood $\mathrm{K}$. The importance of socio-economic status and sex on the prevalence of human pediculosis in government schools children in Lahore, Pakistan. Pakistan Journal of Medical Sciences. 2012; 28(5):952-5.

[14] Goldman L, Tran N. The impact of toxic substances on the poor in developing countries. Washington DC: World Bank; 2002.

[15] Office of the Registrar General and Census Commissioner of India, Ministry of Home Affairs, Government of India. Census of India [Internet]. 2011 [Updated 2019 January 08]. Avaiable from: http://www.censusindia.gov.in/2011census/population_enumeration.html

[16] Sadeghi-Bojd S, Khajeh A. Chronological variations of children poisoning causes in zahedan, South of Iran. International Journal of High Risk Behaviors \& Addiction. 2014; 3(3):e19223. [DOI:10.5812/ijhrba.19223] [PMID] [PMCID]
[17] Van Der Hoek W, Konradsen F. Risk factors for acute pesticide poisoning in Sri Lanka. Tropical Medicine \& International Health. 2005; 10(6):589-96. [DOI:10.1111/j.1365-3156.2005.01416.x] [PMID]

[18] Hamad MH, Adeel AA, Alhaboob AA, Ashri AM, Salih MA. Acute poisoning in a child following topical treatment of head lice (pediculosis capitis) with an organophosphate pesticide. Sudanese Journal of Paediatrics. 2016; 16(1):63-6. [PMID] [PMCID]

[19] Center for Disease Control and Prevention. Treatment. Atlanta: Center for Disease Control and Prevention; 2017.

[20] Tribaldo EB. Residue analysis of carbamate pesticides in water. ChemInform. 2000; 31(52):537-70.

[21] Rosenthal E. The tragedy of Tauccamarca: A human rights perspective on the pesticide poisoning deaths of 24 children in the Peruvian Andes. International Journal of Occupational and Environmental Health. 2003; 9(1):53-8. [DOI:10.1179/oeh.2003.9.1.53] [PMID]

[22] Devi PI, Thomas J, Raju RK. Pesticide consumption in India: A spatiotemporal analysis. Agricultural Economics Research Review. 2017; 30(1):163-72. [DOI:10.5958/0974-0279.2017.00015.5]

[23] Tenenbaum D. Carbofuran under review. Environmental health perspectives. 2008; 116(10):A425. [DOI:10.1289/ehp.116-a425]

[24] Gunnell D, Eddleston M. Suicide by intentional ingestion of pesticides: A continuing tragedy in developing countries. International Journal of Epidemiology. 2003; 32(6):902-9. [DOI:10.1093/ ije/dyg307] [PMID] [PMCID]

[25] Ramsay MA, John Snow MD. Anaesthetist to the queen of England and pioneer epidemiologist. Journal Baylor University Medical Center Proceedings. 2006; 19(1):24-8. [DOI:10.1080/08998280.2 006.11928120] [PMID]

[26] Snow J. On the mode of communication of cholera. Edinburgh Medical Journal. 1856; 1(7):668-70. [PMID] [PMCID]

[27] Carson R. Silent Spring. Boston: Houghton Mifflin Company; 1962

[28] Gunnell D, Fernando R, Hewagama M, Priyangika WD, Konradsen $F$, Eddleston $M$. The impact of pesticide regulations on suicide in Sri Lanka. International Journal of Epidemiology. 2007; 36(6):1235-42. [DOI:10.1093/ije/dym164] [PMID] [PMCID] 